\title{
Skeletal Survey X-Ray
}

National Cancer Institute

\section{Source}

National Cancer Institute. Skeletal Survey X-Ray. NCI Thesaurus. Code C38092.

A procedure used to detect fractures, tumors, or degenerative conditions of the bone. 